\title{
BCBioconjugate BCChemistry
}

Subscriber access provided by UCL Library Services

Communication

A plug-and-play approach for the de novo generation of dually functionalised bispecifics

Antoine Maruani, Peter Szijj, Calise Bahou, João Nogueira, Stephen Caddick, James Richard Baker, and Vijay Chudasama

Bioconjugate Chem., Just Accepted Manuscript • DOI: 10.1021/acs.bioconjchem.0c00002 • Publication Date (Web): 24 Feb 2020

Downloaded from pubs.acs.org on March 2, 2020

Just Accepted

"Just Accepted" manuscripts have been peer-reviewed and accepted for publication. They are posted online prior to technical editing, formatting for publication and author proofing. The American Chemical Society provides "Just Accepted" as a service to the research community to expedite the dissemination of scientific material as soon as possible after acceptance. "Just Accepted" manuscripts appear in full in PDF format accompanied by an HTML abstract. "Just Accepted" manuscripts have been fully peer reviewed, but should not be considered the official version of record. They are citable by the Digital Object Identifier (DOI®). "Just Accepted" is an optional service offered to authors. Therefore, the "Just Accepted" Web site may not include all articles that will be published in the journal. After a manuscript is technically edited and formatted, it will be removed from the "Just Accepted" Web site and published as an ASAP article. Note that technical editing may introduce minor changes to the manuscript text and/or graphics which could affect content, and all legal disclaimers and ethical guidelines that apply to the journal pertain. ACS cannot be held responsible for errors or consequences arising from the use of information contained in these "Just Accepted" manuscripts. 
Title:

A plug-and-play approach for the de novo generation of dually functionalised bispecifics

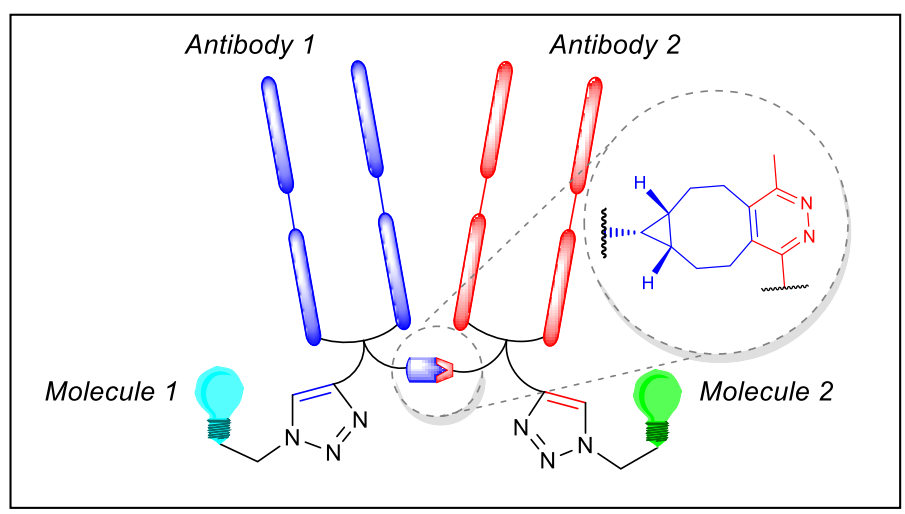




\title{
A plug-and-play approach for the de novo generation of dually functionalised bispecifics
}

\author{
Antoine Maruani ${ }^{\dagger}$, Peter A. Szijj ${ }^{\dagger}$, Calise Bahou ${ }^{\dagger}$, João C. F. Nogueira ${ }^{\dagger}$, Stephen Caddick ${ }^{\dagger}$, James R.

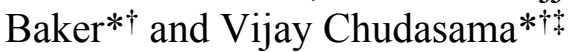 \\ $\dagger$ Department of Chemistry, University College London, 20 Gordon Street, WC1H 0AJ, London, UK. \\ * Research Institute for Medicines (iMed.ULisboa), Faculty of Pharmacy, Universidade de Lisboa, \\ 1649-003 Lisbon, Portugal. \\ * e-mails: v.chudasama@ucl.ac.uk; j.r.baker@ucl.ac.uk
}

\begin{abstract}
Diseases are multifactorial, with redundancies and synergies between various pathways. However, most of the antibody-based therapeutics on the market interact with only one target thus limiting their efficacy. The targeting of multiple epitopes could improve the therapeutic index of treatment and counteract mechanisms of resistance. To this effect, a new class of therapeutics emerged: bispecific antibodies.

Bispecific formation using chemical methods is rare and low yielding and/or requires a large excess of one of the two proteins to avoid homodimerisation and heterogeneity. In order for chemically prepared bispecifics to deliver their full potential, high-yielding, modular and reliable cross-linking technologies are required. Herein, we describe a novel approach not only for the rapid and high-yielding chemical generation of bispecific antibodies from native antibody fragments, but also for the site-specific dual functionalisation of the resulting bioconjugates. Based on orthogonal clickable functional groups, this strategy enables the assembly of functionalised bispecifics with controlled loading in a modular and convergent manner.
\end{abstract}

\section{Introduction}

Monoclonal antibodies (mAbs) have the ability to recognise the epitope of an antigen with high specificity. MAbs that bind to a cancer cell and induce an immune response are extensively utilised in cancer treatments. ${ }^{l}$ Nevertheless, although some naked antibodies (e.g. Herceptin) have revolutionised certain cancer therapies they often fail to induce sufficient anti-tumour activity on their own- and there is an impetus to develop modified variants that can overcome this limitation. ${ }^{1,2}$

Advances in the development of the mAbs format have been made -for example the use of fragments and development of functionalised mAbs. These have led to improvements in their efficacy and have overcome many barriers. ${ }^{3}$ Despite these advances, the safety and efficacy profile of mAbs biomolecules still requires further work to develop approaches to broaden their therapeutic index.

With advances in mAbs format, has come the possibility of moving away from the conventional monospecific approach and developing antibodies to target multiple targets simultaneously. This is potentially attractive as diseases are multifactorial, with redundancies and synergies between various pathways. ${ }^{4}$ Moreover, targeting multiple epitopes could potentially improve the therapeutic index of treatment (e.g. by reducing systemic toxicity) and counteract mechanisms of tumour survival..$^{5}$ To address this opportunity in the mid-1980s, a new class of therapeutics emerged: bispecific antibodies (BsAbs). 6, 7 The principle behind BsAbs is to target two epitopes through a single entity and 
simultaneously affect multiple pathways to increase overall efficacy.

The production of high quality BsAbs is non-trivial and in principle they can be produced either by chemically linking two proteins together (e.g. disulfide exchange on native antibody, crosslinking via heterobifunctional linker) or by protein, cellular, and genetic engineering (e.g. quadroma approach, genetic recombination). ${ }^{4,8,9}$ When compared to biological approaches, chemical methods tend to have the advantage of being more general and straightforward as they typically do not require specific engineering for each protein of interest thus enabling the use of commercially available mAbs as precursors which decreases overall costs and time required. Initially, clinical trials with chemicallylinked antibodies and antibody fragments were promising, but their costly preparation, low final product yields, time-consuming purification and product heterogeneity ultimately prevented further development. ${ }^{10-14}$ Thanks to advances in protein engineering (e.g. recombinant DNA technologies), the production of BsAbs via biological approaches superseded chemical ones, ${ }^{9}$ however with recent development in site-specific modification of proteins and bioorthogonal reactions, chemical methods for protein-protein preparation are now re-surfacing. ${ }^{15-22}$ Nevertheless, bispecific formation using such methods from non-engineered scaffolds are rare and none of the current bispecifics in the clinic are made by chemical means. They often have limited conversion or require an excess of one of the two proteins to avoid homodimerisation and heterogeneity, are restricted to $\operatorname{IgG} 2$ antibodies and do not enable further site-selective functionalisation. ${ }^{18,23,24}$ In order for chemically-prepared bispecifics to deliver their full potential, high-yielding, modular and reliable cross-linking technologies are therefore required.

Bioorthogonal chemistry has revolutionised the field of chemical biology by providing powerful chemical tools for the selective modification of biomolecules. Click chemistry and bioorthogonal chemistry overlap significantly, reflecting the same underlying chemical principles, i.e. regioselective conjugation under mild conditions. ${ }^{25}$ In practice, click reactions have been used extensively in a biological context, particularly for the site-selective introduction of a single chemical moiety. However, the deployment of the same approach for the site-selective and bioorthogonal dual modification of biomolecules is rare, ${ }^{26}$ especially in the context of non-engineered scaffolds. Although the introduction of multiple modules enables a plethora of permutations/combinations and can generate a variety of bioconjugates with many potential applications, it remains a challenge. ${ }^{26}$

Recently, we described a new approach to the synthesis of doubly modified antibodies with nonproteinogenic cargoes. ${ }^{27}$ Our approach was a chemoselective "dual click" strategy based on dibromopyridazinedione (PD) scaffolds which have then been employed extensively to functionally rebridge disulfide, e.g. in the generation of $\mathrm{ADCs},{ }^{28}$ antibody conjugates, ${ }^{29-31}$ antibody-directed photosensitisers, ${ }^{32,}{ }^{33}$ and a targeted nanotherapeutic. ${ }^{34}$ These applications highlighted some key features of this platform, e.g. site-selectivity, long-term blood plasma stability, resistance to hydrolysis, compatibility with common mild reducing reagents [tris(2-carboxyethyl)phosphine - TCEP], ${ }^{29}$ and retention of binding capability of the modified antibody. However, these applications did not take advantage of the double click capability of PDs in the context of forming protein-protein conjugates. This represents a challenge due to the steric hindrance that needs to be overcome when attaching large molecules to each other, and the need to use stoichiometric (or-near stoichiometric) amounts of both reagents. These disfavourable conditions need to be overcome by careful optimisation and experiment design.

Herein, we describe a novel modular approach both for the rapid synthesis of bispecific antibodies from native antibody fragments, and for the site-specific dual functionalisation of the resulting bioconjugates. By incorporating orthogonal clickable functionalities, we are able to rapidly assemble 
functionalised bispecifics with controlled loading $(0,1,2$, or " $1+1$ ") in a modular and convergent manner.

\section{Results}

Three FDA-approved monoclonal antibodies, i.e. rituximab, cetuximab and trastuzumab, were selected to evaluate our new approach. We selected Fab fragments for the study as they retain the targeting specificity of full antibodies, usually have better tissue penetration properties, and can be produced more economically. ${ }^{35}$

Rituximab is a chimeric mAb against CD20 which is found on the surface of B cells. Rituximab is widely used to treat autoimmune diseases and cancer, and fragments derived from rituximab have been engineered for use in a variety of bispecific antibodies in order to help bypass resistance mechanisms. ${ }^{36-38}$

Cetuximab and trastuzumab are both monospecific antibodies that bind to and interfere with signalling of HER family members (HER1 and HER2, respectively). They have been successfully used in the treatment of a variety of cancers (e.g. breast cancer, metastatic colorectal cancer, metastatic non-small cell lung cancer). BsAbs directed at multiple members of the HER family are being pursued with the aim of improving therapeutic efficacy. ${ }^{39,40}$

\section{Design of linkers for bispecific formation}

The choice and design of linkers were key to achieve a method that is modular, reliable, straightforward and widely applicable to non-engineered scaffolds. It represented two independent yet related challenges in chemical orthogonality and bioorthogonality as it had to not only enable efficient crosslinking of two antibody fragments, but it should also allow for further dual functionalisation with small molecules of interest.

To design the adequate linkers for protein cross linking, four main parameters needed to be taken into consideration:

- All reactions needed to be click compatible to enable modularity;

- The click reaction to assemble the bispecific by reacting the two proteins needed to be rapid and quantitative even with near stoichiometric quantities;

- A long and flexible enough spacer would be needed to prevent a potential entropic barrier to the reaction between two proteins;

- The linkers had to be stable to the various conditions used throughout the entire process (e.g. $\mathrm{pH}$, temperature, redox).

To this end, several click approached were trialled (i.e. CuAAC, SPAAC with electron rich and electron poor azide/alkyne combination and Michael addition, data not shown) but all resulted in partial conversion to the desired conjugate. Thus, we decided to focus our efforts on strain-promoted inverse electron demand Diels-Alder cycloaddition (SPIEDAC), a widely used bioorthogonal reaction known for its fast reaction kinetics. ${ }^{41}$ Classically, the two partners in SPIEDAC are a strained alkene (e.g. trans-cyclooctene [TCO], norbornene) and an electron-poor diene (e.g. tetrazine) but stability over an extended period with TCO is often a concern ${ }^{41}$ and the reactivity of norbornene towards tetrazine is limited (i.e. reaction rates of $c a .1 \mathrm{M}^{-1} \mathrm{~s}^{-1}$ ). ${ }^{42,43}$ It was therefore decided to mitigate this risk by using a slower yet more stable partner, namely electron-rich strained alkyne bicyclo[6.1.0]nonyne (BCN). $\mathrm{BCN}$ is commonly used in strain-promoted azide-alkyne click chemistry ${ }^{44}$ with rates of $c a .1 \mathrm{M}^{-1} \mathrm{~s}^{-1}$. 
Contrary to most other strained alkyne (e.g. DIBAC, DIBO) which are suboptimal partners for SPIEDACs, BCN is an electron-rich strained alkyne which raises its HOMO and thus reduces the activation energy in inverse demand Diels-Alder reactions. For this reason, BCN has been used in SPIEDAC with reaction rates $>20000 \mathrm{M}^{-1} \mathrm{~s}^{-1}$ under aqueous conditions when applied for protein labelling ${ }^{45}$ and therefore represents a promising partner for protein-protein crosslinking.

The substituents on the tetrazine ring are also a key factor in SPIEDACs. Electron-withdrawing substituents such as pyrimidine greatly increase the rate of reaction (by lowering the energy of the $\mathrm{LUMO}_{\text {tetrazine}}$ ) but they may also promote their degradation. ${ }^{46}$ Thus a trade-off between stability and reactivity is often needed depending on the application. Both highly reactive yet less stable tetrazine 1 and highly stable yet less reactive tetrazine $\mathbf{2}$ (Figure 1) were compared for protein-protein formation via SPIEDAC and it was found that for our approach, high stability was preferred over very fast kinetics. Indeed, with highly reactive tetrazine $\mathbf{1}$ or with a partner with limited reactivity (e.g. azides), only partial conversion was observed (data not shown) thus greatly limiting the yield of the reaction.

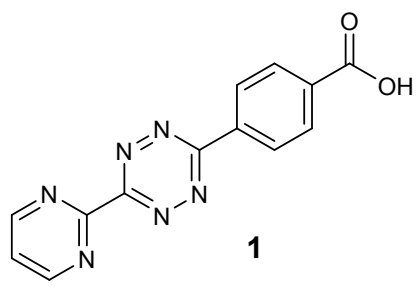

High reactivity, low stability

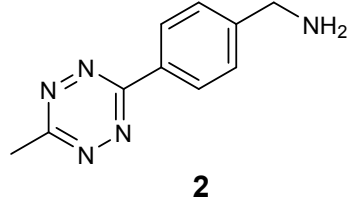

Lower reactivity, high stability

Figure 1: Tetrazines compared for their efficacy for SPIEDAC between proteins.

Two PDs were thus prepared following our recently described protocol, ${ }^{47}$ one bearing a $\mathrm{BCN}$ handle and the other bearing tetrazine $\mathbf{2}$. To reduce aggregation, minimize steric hindrance, and enhance solubility both linkers incorporated a short PEG spacer.

Briefly, starting from our previously described reactive intermediate 3 for divergent synthesis of PDs, ${ }^{47}$ commercially available BCN-amine was coupled to NHS-PD 3 and gave BCN-PD 4 in $72 \%$ yield. The synthesis of Tetrazine-PD 7 started from the preparation of tetrazine $\mathbf{5}^{48}$ which can be obtained in one step from commercially available material. Carboxylic acid $\mathbf{5}$ was then coupled to bis(amine) PEG (i.e. $O, O^{\prime}$-bis(3-aminopropyl)diethylene glycol) in $63 \%$ yield. The resulting amine 6 was then attached to NHS-PD 3 and gave Tetrazine-PD 7 in 62\% yield (Figure 2). 

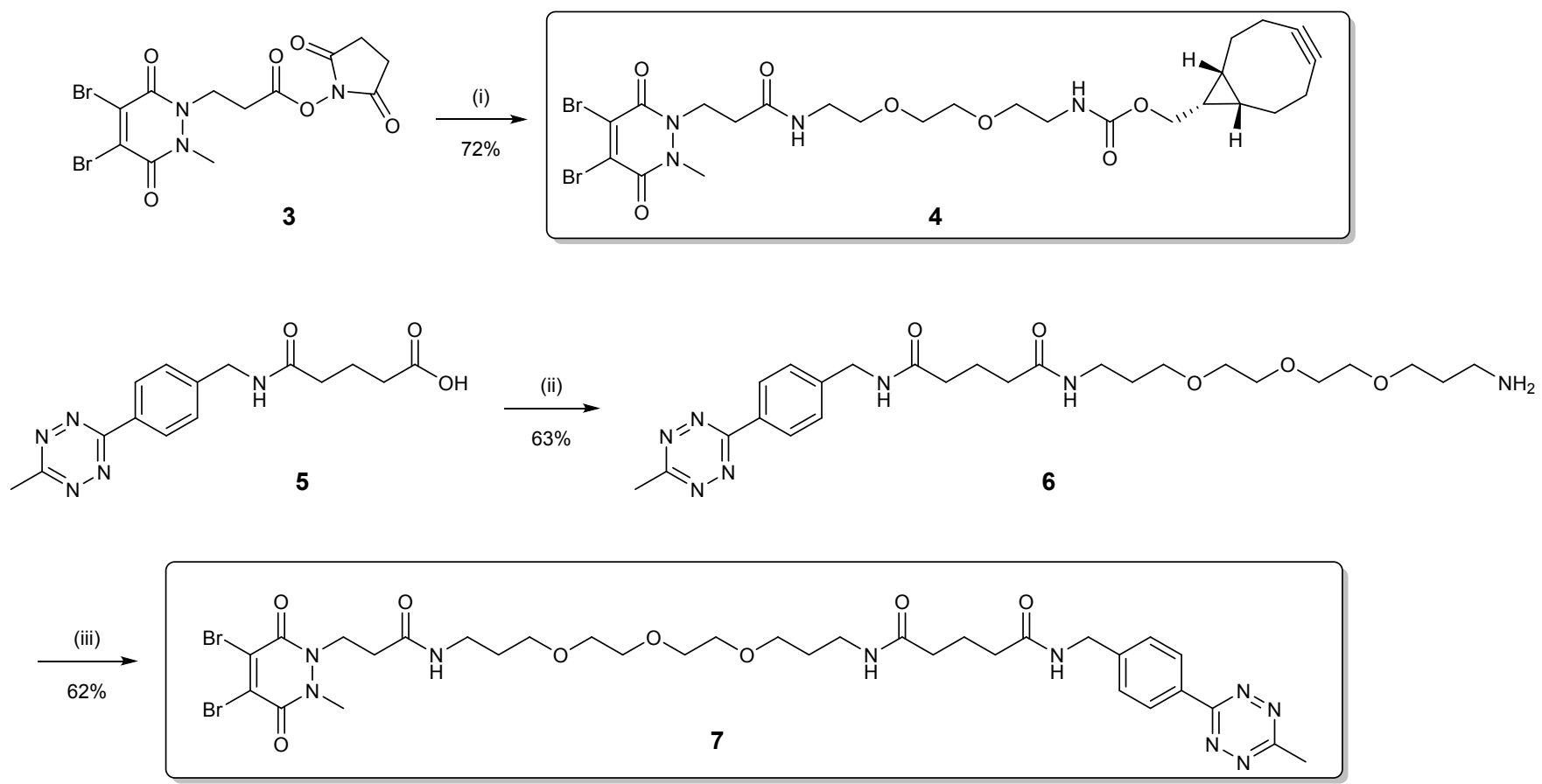

Figure 2: Reagents and conditions: (i) BCN-amine ( $N-[(1 R, 8 S, 9 s)$-bicyclo[6.1.0]non-4-yn-9ylmethyloxycarbonyl]-1,8-diamino-3,6-dioxaoctane), MeCN, rt, 16 h; (ii) bis(amine) PEG, HATU, $\mathrm{NEt}_{3}, \mathrm{CH}_{2} \mathrm{Cl}_{2}, \mathrm{rt}, 16 \mathrm{~h}$; (iii) 3, $\mathrm{MeCN}, \mathrm{rt}, 16 \mathrm{~h}$.

Tetrazine-PD 7 and BCN-PD 4 were then appraised for the functional rebridging of a Fab fragment of trastuzumab $\left(\mathrm{Fab}_{\mathrm{TRA}}\right)$. Both conversions to $\mathrm{Fab}_{\mathrm{TRA}}-\mathrm{BCN} 8$ and $\mathrm{Fab}_{\mathrm{TRA}}-$ Tetrazine 9 occurred in near quantitative yield (Figure 3) with no thiol-yne addition. Removal of the small excess of the reducing agent used to reduce the disulfide bonds (i.e. TCEP) proved to be essential for the formation of $\mathrm{Fab}_{\mathrm{TRA}}-$ Tetrazine $\mathbf{9}$ as tetrazines can be reduced by such reagents. Following the isolation of $\mathbf{8}$ and $\mathbf{9}$, conditions to form $\mathrm{Fab}_{\mathrm{TRA}}-\mathrm{Fab}_{\mathrm{TRA}}$ homodimer were trialled. 


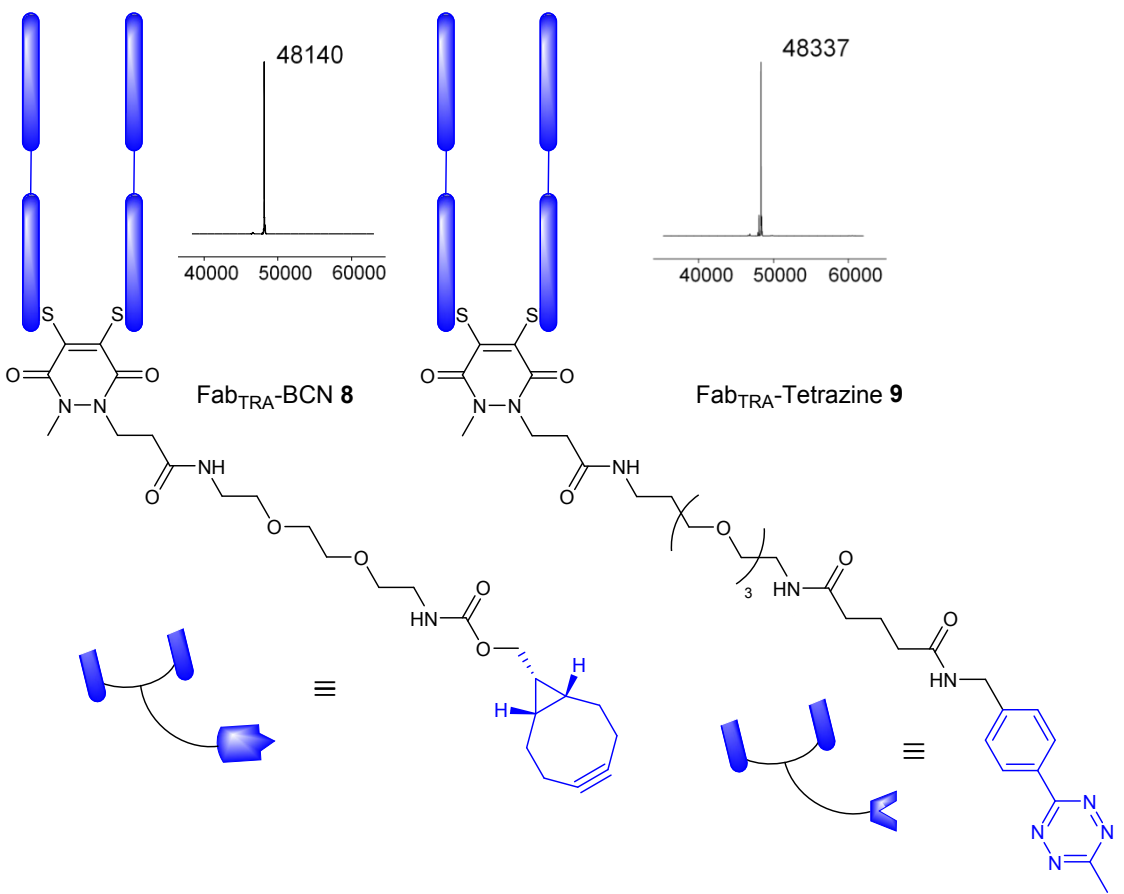

Figure 3: Structures of $\mathrm{Fab}_{\mathrm{TRA}}-\mathrm{BCN} \mathbf{8}$ and $\mathrm{Fab}_{\mathrm{TRA}}-$ Tetrazine 9.

To effect near quantitative conversion whilst using stoichiometric amount of each $\mathrm{Fab}_{\mathrm{TRA}}$, three key variables were identified: concentration, $\mathrm{pH}$, and temperature. High concentration would increase the reaction rate but increase potential aggregation whilst low concentration would avoid issues with aggregation but decrease the conversion of the reaction by increasing the residency time (and potential degradation) of BCN and/or tetrazine in buffer. Similarly, high temperature would promote degradation but also increase the reaction rate whilst low temperature would decrease degradation but also reaction rate. Even though $\mathrm{pH}$ has no observable impact on SPIEDACs kinetics, ${ }^{46}$ tetrazines are known to degrade faster in basic $\mathrm{pH}$, thus slightly acidic $\mathrm{pH}$ was preferred. ${ }^{49}$ Following optimisation of these parameters, it was found that reaction at $\mathrm{pH} 7$ or 8 , at low temperature or at concentrations below $60 \mu \mathrm{M}$ did not reach completion due to competing degradation but when reacting the two partners at $100 \mu \mathrm{M}, 30{ }^{\circ} \mathrm{C}, \mathrm{pH} 6.0$ near quantitative conversion using near stoichiometric amount (i.e. 1.1 equivalents) of each $\mathrm{Fab}_{\text {TRA }}$ could be obtained after $12 \mathrm{~h}$ (Figure 4).

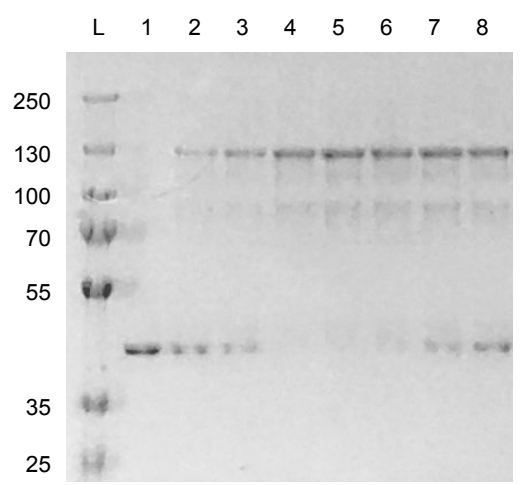

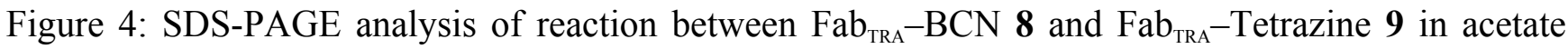
buffer $\mathrm{pH} 6.0$ at $30{ }^{\circ} \mathrm{C}$ for $12 \mathrm{~h}$. $\mathrm{L}-$ ladder; lane $1-\mathbf{8}+0$ eq. 9; lane $2-\mathbf{8}+0.5$ eq. $\mathbf{9}$; lane $3-\mathbf{8}+0.7$ eq. 9; lane $4-\mathbf{8}+0.9$ eq. 9 ; lane $5-\mathbf{8}+1.0$ eq. 9 ; lane $6-\mathbf{8}+1.1$ eq. 9 ; lane $7-\mathbf{8}+1.3$ eq. 9 ; lane $5-$ $8+1.5$ eq. 9 . 
Using these optimal parameters, $\mathrm{Fab}_{\mathrm{TRA}}-\mathrm{BCN} \mathbf{8}$ and $\mathrm{Fab}_{\mathrm{TRA}}-$ Tetrazine 9 were reacted. The reaction reached completion with no remaining $\mathrm{Fab}_{\mathrm{TRA}}-\mathrm{BCN} 8$ after 12 h. Following purification, $\mathrm{Fab}_{\mathrm{TRA}}-\mathrm{Fab}_{\mathrm{TRA}}$ homodimer 10 was isolated in 55-65\% yield (Figure 5).
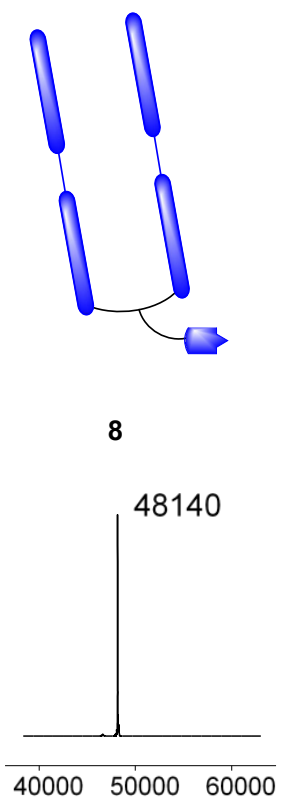
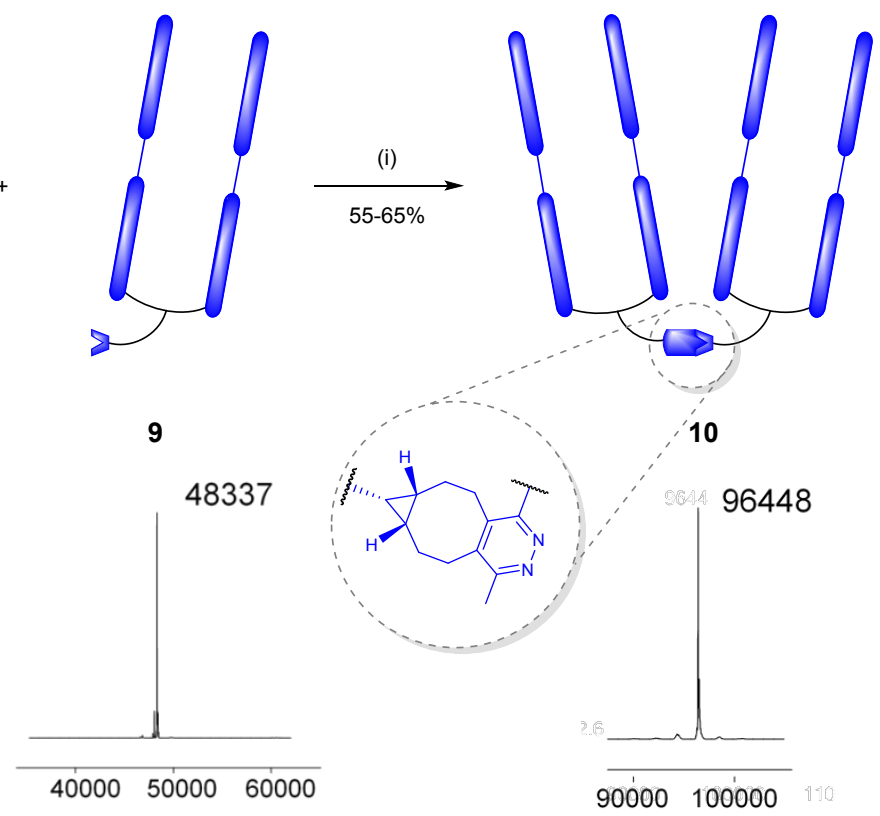

Figure 5: Reagents and conditions: (i) $100 \mu \mathrm{M}$, acetate buffer $\mathrm{pH} 6.0,30{ }^{\circ} \mathrm{C}, 12 \mathrm{~h}$.

With these optimal conditions in hand, the method was applied to cetuximab Fab (Fab $\left.{ }_{\mathrm{CET}}\right)$ and rituximab $\mathrm{Fab}\left(\mathrm{Fab}_{\mathrm{RIT}}\right)$ to generate chemically-prepared bispecifics from non-engineered antibodies. First, $\mathrm{Fab}_{\mathrm{TRA}}-\mathrm{BCN} \mathbf{8}, \mathrm{Fab}_{\mathrm{CET}}$-Tetrazine 11 and $\mathrm{Fab}_{\mathrm{RIT}}$-Tetrazine 12 were prepared in near quantitative yield. Then $\mathrm{Fab}_{\mathrm{TRA}}-\mathrm{BCN} \mathbf{8}+\mathrm{Fab}_{\mathrm{RIT}}$-Tetrazine 12, and $\mathrm{Fab}_{\mathrm{TRA}}-\mathrm{BCN} \mathbf{8}+\mathrm{Fab}_{\mathrm{CET}}-$ Tetrazine 11 were reacted for $12 \mathrm{~h}$ at $100 \mu \mathrm{M}, 30^{\circ} \mathrm{C}, \mathrm{pH} 6.0$.

Gratifyingly, the conditions translated well to other antibodies and BsAbs $\mathrm{Fab}_{\mathrm{TRA}}-\mathrm{Fab}_{\mathrm{CET}} \mathbf{1 3}$ and $\mathrm{Fab}_{\mathrm{TRA}}-$ $\mathrm{Fab}_{\text {RIT }} 14$ were obtained in good purity in $71 \%$ and $78 \%$ isolated yield respectively without the need for SEC purification (Figure 6). These promising results demonstrate the versatility of our approach in the generation of bispecifics in near quantitative conversion and high isolated yield from non-engineered antibodies and led to further investigation into the functionalisation of the chemically-formed proteinprotein conjugates. 

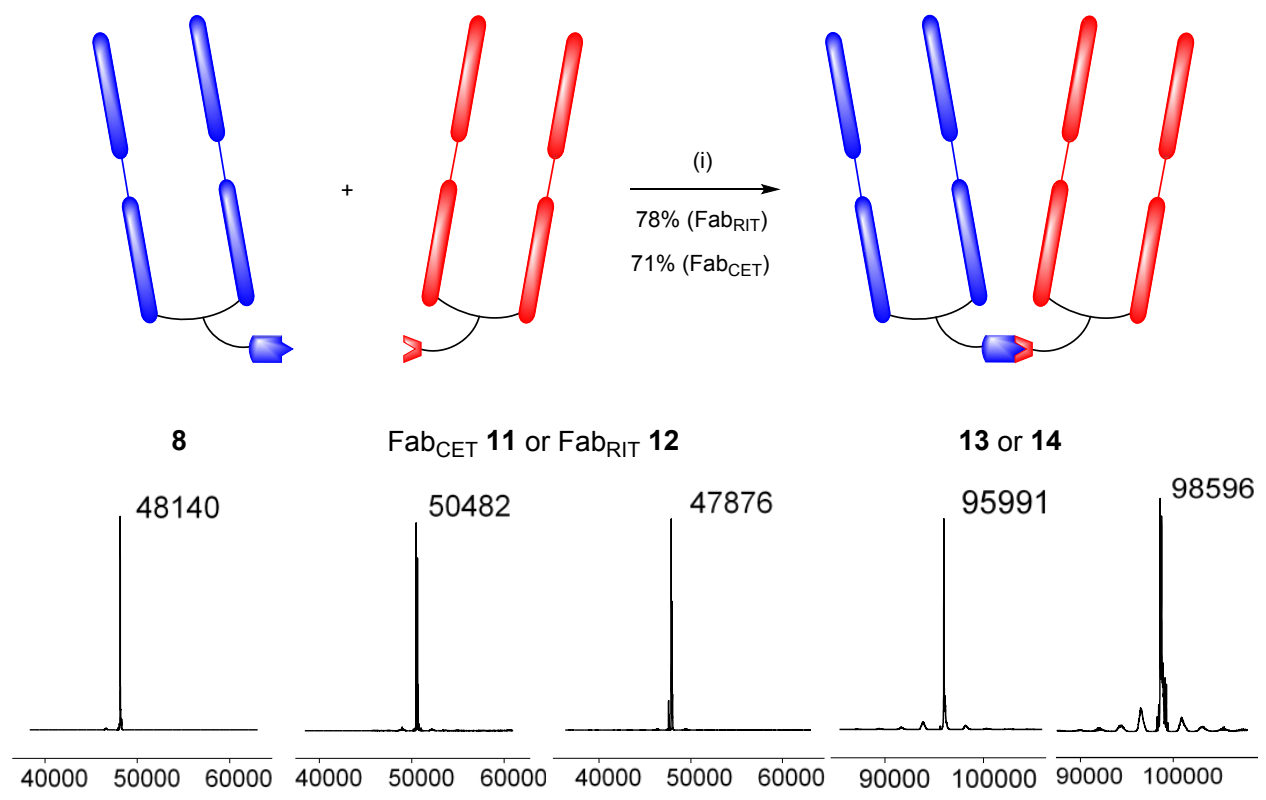

Figure 6: Reagents and conditions: (i) $[100 \mu \mathrm{M}]$, acetate buffer $\mathrm{pH} 6.0,30^{\circ} \mathrm{C}, 12 \mathrm{~h}$.

\section{Functionalisation of the bispecific with controlled loading}

To further functionalise the bispecific, the methyl group of PDs 4 and 7 needed to be replaced by another reactive functional group. This new group would need to be compatible with the chemical partners and conditions used to assemble the bispecific and yet amenable to facile reaction with a variety of commercially available payloads (e.g. fluorophores, drugs, biotin, chelators).

We have previously shown that terminal alkynes and strained alkynes can co-exist on a PD and can be independently functionalised, provided the strained alkyne is reacted first. ${ }^{27}$ Similar orthogonality has been observed with tetrazines and terminal alkynes. These observations led to the synthesis of two novel PDs bearing unstrained alkyne on one of the nitrogen atoms and BCN or tetrazine $\mathbf{2}$ on the other. Briefly, the synthesis of $\mathbf{4}$ and $\mathbf{7}$ was adapted to add this second reactive species; starting from hydrazine alkyne 16 obtained via selective alkylation of hydrazine 15, a second alkylation led to disubstituted hydrazine 17, which was converted to PD 18 by condensation with dibromomaleic acid. Following activation with NHS, 19 was reacted with BCN-amine or tetrazine amine $\mathbf{6}$ to give PD 20 in $58 \%$ yield and PD 21 in 43\% yield, respectively (Figure 7). 

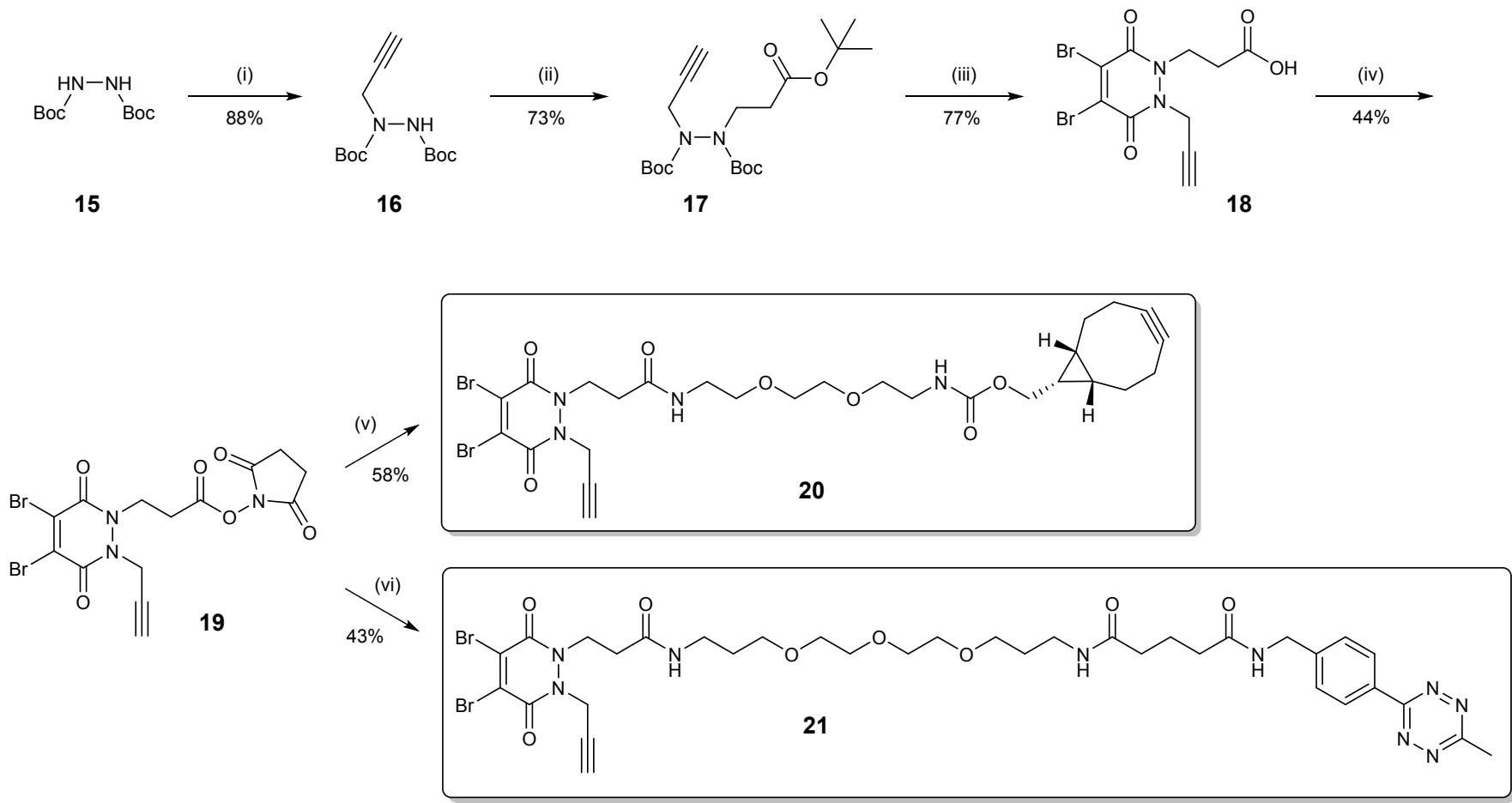

Figure 7: Reagents and conditions: (i) Propargyl bromide, $\mathrm{TBAB}$, toluene $/ 5 \% \mathrm{NaOH}_{(\mathrm{aq})}$, rt, $16 \mathrm{~h}$; (ii) $t$ butyl acrylate, $t$ - $\mathrm{BuOH}, 10 \% \mathrm{NaOH}_{(\mathrm{aq})}, 6{ }^{\circ} \mathrm{C}, 24 \mathrm{~h}$; (iii) dibromomaleic acid, AcOH, reflux, $4 \mathrm{~h}$; (iv) DCC, THF, $0{ }^{\circ} \mathrm{C}$ for 30 min then NHS, rt, 16 h; (v) BCN amine, MeCN, rt, 16 h; (vi) 6, MeCN, rt, 16 h.

BCN-Alkyne-PD 20 and Tetrazine-Alkyne-PD 21 were then appraised for the functional rebridging of $\mathrm{Fab}_{\text {TRA }}$ and $\mathrm{Fab}_{\text {RIT }}$. The optimised conditions translated well to these novel PDs and both $\mathrm{Fab}_{\text {TRA }}-\mathrm{BCN}-$ Alkyne 22, $\mathrm{Fab}_{\mathrm{TRA}}$-Tetrazine-Alkyne $\mathbf{2 3}$ and $\mathrm{Fab}_{\mathrm{RIT}}$-Tetrazine-Alkyne $\mathbf{2 4}$ were isolated in near quantitative yield (see SI for details).

To optimise copper(I)-catalysed azide-alkyne cycloaddition (CuAAC) conditions and appraise the stability of the additional alkyne moiety, the click strategy was attempted on a chemically formed $\mathrm{Fab}_{\text {TRA }}-\mathrm{Fab}_{\mathrm{TRA}}$ homodimer bearing two additional alkyne moieties. This homodimer was obtained by functionally rebridging $\mathrm{Fab}_{\mathrm{TRA}}$ with the novel PDs to prepare $\mathrm{Fab}_{\mathrm{TRA}}-\mathrm{BCN}-\mathrm{Alkyne} 22$ and $\mathrm{Fab}_{\mathrm{TRA}}-$ Tetrazine-Alkyne $\mathbf{2 3}$ which were then reacted under optimised conditions to yield $\mathrm{Fab}_{\text {TRA }}-\mathrm{Alkyne}-$ $\mathrm{Fab}_{\mathrm{TRA}}-\mathrm{Alkyne} 25$ (Figure 8). To enable additional readout of the CuAAC reaction by UV-Vis spectrometry, a commercially available azide-functionalised fluorophore (i.e. AlexaFluor488 [AF488] azide) was selected as the first payload. $\mathrm{Fab}_{\mathrm{TRA}}-\mathrm{Alkyne}_{\mathrm{A}} \mathrm{Fab}_{\mathrm{TRA}}-\mathrm{Alkyne} \mathbf{2 5}$ was subjected to $\mathrm{CuAAC}$ conditions, the reaction proceeded with complete conversion with no unreacted $\mathrm{Fab}_{\mathrm{TRA}}-\mathrm{Alkyne}_{\mathrm{k}}-\mathrm{Fab}_{\mathrm{TRA}}-$ Alkyne 25 and thus, $\mathrm{Fab}_{\mathrm{TRA}}-\mathrm{AF} 488-\mathrm{Fab}_{\mathrm{TRA}}-\mathrm{AF} 48827$ was isolated in high purity in 56\% yield over two steps. Following analysis by LC-MS and UV-Vis spectrometry, a loading of 2 was confirmed (Figure 8 and SI for details).

To demonstrate the potential for controlled loading, a BsAb bearing a single additional alkyne moiety was generated by reaction of $\mathrm{Fab}_{\mathrm{TRA}}-\mathrm{BCN} 8$ and $\mathrm{Fab}_{\mathrm{RIT}}$-Tetrazine-Alkyne 24 (Figure 8). BsAb Fab $\mathrm{TRA}_{\text {TR }}$ $\mathrm{Fab}_{\mathrm{RIT}}$-Alkyne 26 was obtained in $75 \%$ yield and was then subjected to CuAAC conditions. Fab $\mathrm{TRA}_{\mathrm{TRA}}$ $\mathrm{Fab}_{\text {RIT }}-\mathrm{AF} 488$ bispecific 28 was isolated in high purity in $82 \%$ yield. Following analysis by LC-MS, a 
loading of 1 was confirmed (Figure 8). Similarly, when reacting $\mathrm{Fab}_{\mathrm{TRA}}-\mathrm{BCN} 8$ or Fab $\mathrm{TRA}_{\mathrm{TR}}-\mathrm{BCN}-\mathrm{Alkyne}$ 22 with $\mathrm{Fab}_{\mathrm{CET}}-$ Tetrazine-Alkyne, "clickable" BsAbs $\mathrm{Fab}_{\mathrm{TRA}}-\mathrm{Fab}_{\mathrm{CET}}-$ Alkyne and $\mathrm{Fab}_{\mathrm{TRA}}-$ Alkyne$\mathrm{Fab}_{\mathrm{CET}}-$ Alkyne were obtained in high yield and purity (see SI for details).

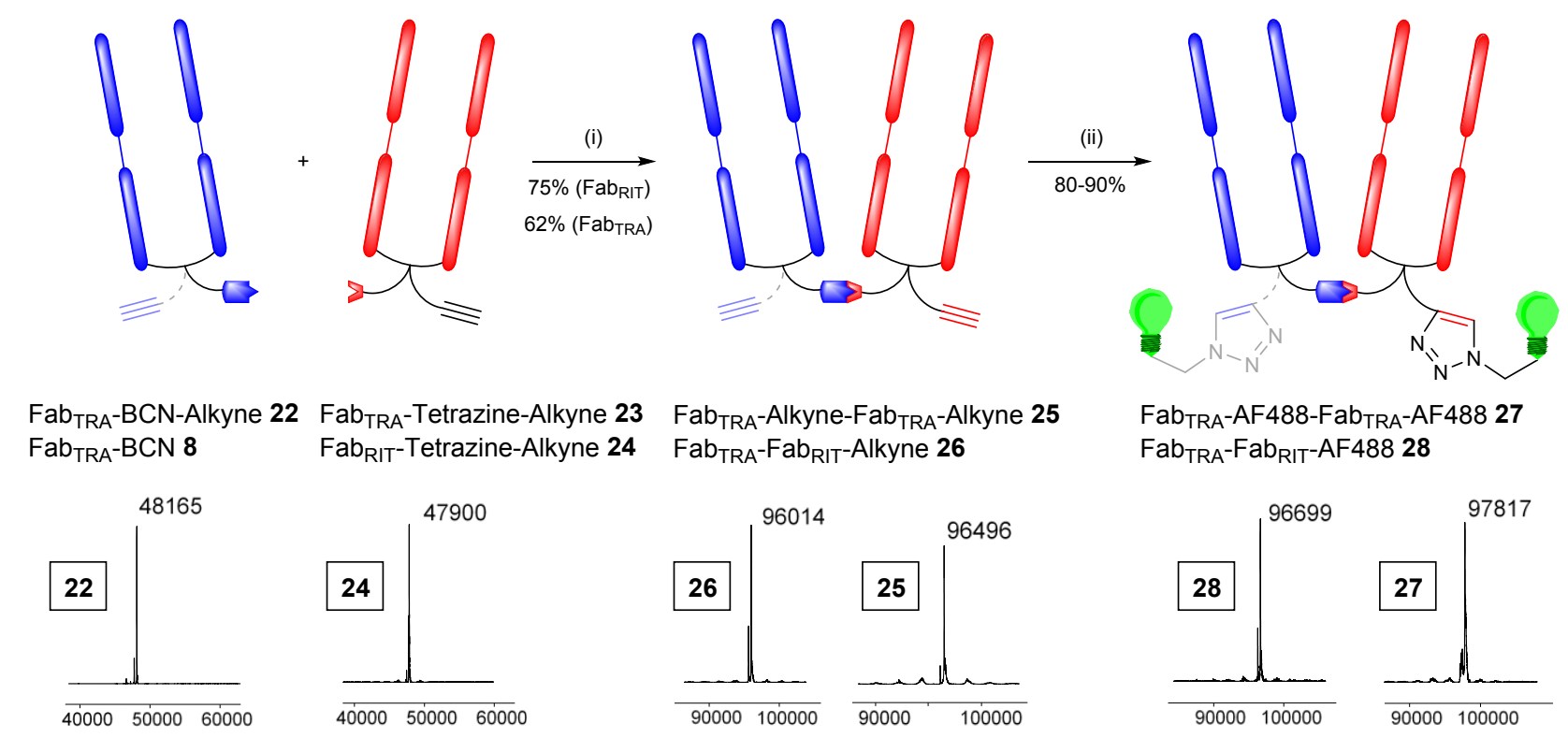

Figure 8: Reagents and conditions: (i) acetate buffer $\mathrm{pH} 6.0,30{ }^{\circ} \mathrm{C}, 12 \mathrm{~h}$; (ii) $\mathrm{AF} 488$ azide, $\mathrm{CuSO}_{4}$, THPTA, sodium ascorbate, phosphate buffer $\mathrm{pH} 7.0,25^{\circ} \mathrm{C}, 1 \mathrm{~h}$. The smaller peak observed is due to $\mathrm{Fab}_{\mathrm{RIT}}$ showing as two peaks by LCMS (see SI for details).

Interestingly, tetrazines have been shown to withstand CuAAC under certain conditions. It was envisaged that this would allow for the functionalisation of the alkyne of $\mathrm{Fab}_{\mathrm{RIT}}$-Tetrazine-Alkyne $\mathbf{2 4}$ prior to bispecific formation by SPIEDAC thus enabling the addition of a second (different) azide after reacting the tetrazine with $\mathrm{BCN}$. For this strategy, controlling the amounts of copper and sodium ascorbate was critical to alleviate tetrazine reduction. Following optimisation, 1 equivalent of copper(II) sulfate and 10 equivalents of sodium ascorbate were found to quantitatively yield the desired cycloaddition product without detectable tetrazine degradation by LCMS. The unaffected tetrazine from $\mathrm{Fab}_{\text {RIT }}$-Tetrazine-AF488 29 was then reacted with $\mathrm{Fab}_{\mathrm{TRA}}-\mathrm{BCN}$-Alkyne 22 to form bispecific functionalised with AF488 with a remaining alkyne handle, $\mathrm{Fab}_{\mathrm{RIT}}-\mathrm{AF} 488-\mathrm{Fab}_{\mathrm{TRA}}-$ Alkyne 30 (Figure 9).

To analyse the effectiveness of the "dual click" approach on the chemically prepared monofunctionalised BsAb 30, a second light absorbing moiety that absorbs at a distinct wavelength to AF488 was needed to enable facile analysis by UV-visible spectrometry of the loading of each fluorophore. To this end, a photostable, water-soluble, cyanine-based fluorophore with a maximum absorbance at $673 \mathrm{~nm}$ (sulfo-Cy5.5) was selected and reacted with 30 to yield dually-functionalised bispecific $\mathrm{Fab}_{\text {RIT }}{ }^{-}$ AF488-Fab ${ }_{\text {TRA }}-\mathrm{Cy} 5.531$ in 55\% yield over three steps. The 1:1 loading of each fluorophore was confirmed by UV-Vis spectrometry and LC-MS (Figure 10) thus demonstrating the modularity of the approach to obtain a loading of $0,1,2$ or " $1+1$ ". Thus, in essence, what we have been able to achieve is the development of: (i) a robust method in which one can form bispecifics using well-tolerated "click" chemistry; (ii) a protocol that uses Fabs that can be readily generated from native full antibodies (i.e. no antibody engineering is required); and (iii) a procedure in which said bispecifics can be functionalised with multiple entities in a modular fashion with exquisite control over their loading(s). 
a)

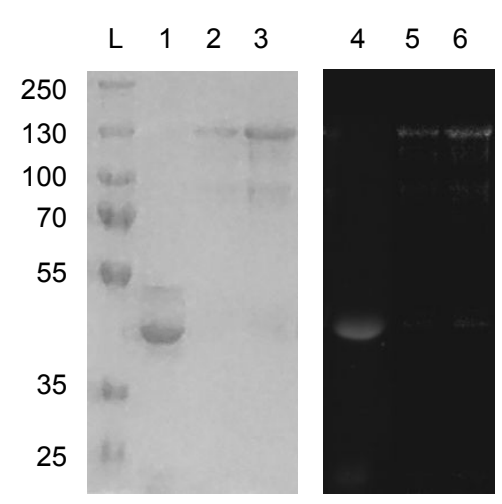

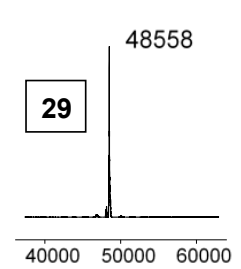
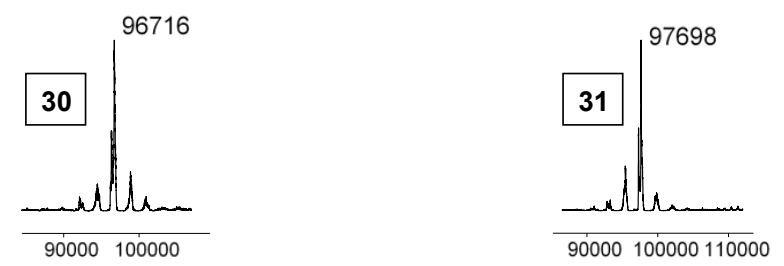

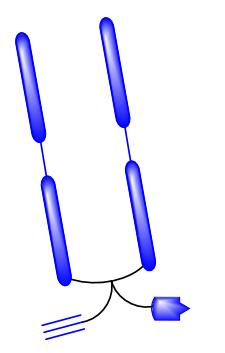

22
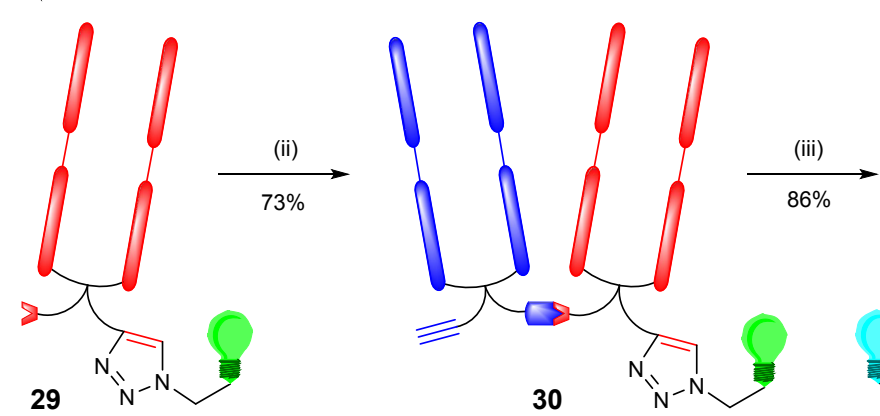

90000100000110000

Figure 9: Reagents and conditions: (i) AF488 azide, $\mathrm{CuSO}_{4}$, THPTA, sodium ascorbate, phosphate

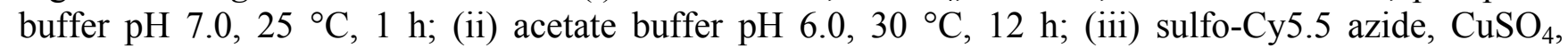
THPTA, sodium ascorbate, phosphate buffer $\mathrm{pH} 7.0, \mathrm{rt}, 1 \mathrm{~h}$.

b)

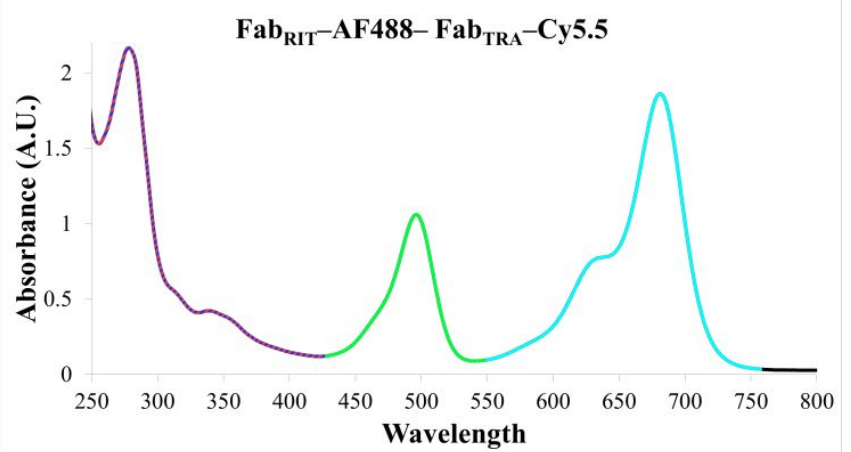

Figure 10: (a) SDS-PAGE analysis of reaction between $\mathrm{Fab}_{\mathrm{TRA}}-\mathrm{BCN}-\mathrm{Alkyne} 22$ and $\mathrm{Fab}_{\mathrm{RIT}}-$ Tetrazine- $^{-}$ AF488 29. L - ladder; lane 1 - 29; lane 2-30; lane 3-31; in-gel fluorescence lane 4-29; lane 5-30; lane $6-\mathbf{3 1}$; (b) UV-Vis analysis of $\mathrm{Fab}_{\mathrm{RIT}}-\mathrm{AF} 488-\mathrm{Fab}_{\mathrm{TRA}}-\mathrm{Cy} 5.531$.

\section{Binding affinity}

As previously described, conjugates obtained from PD-based antibody modifications are stable over a wide range of conditions (e.g. $\mathrm{pH}$, temperature, serum) for protracted periods and do not affect binding nor internalisation of the antibody of interest as the modification is distal from the binding site. ${ }^{27,28,47}$ When compared to their parent monospecific Fab by ELISA, bispecific 31 indeed showed no decrease in $\mathrm{K}_{\mathrm{D}}$ for each individual Fab arm (Figure 11). Following this, we wanted to confirm that binding of both Fab arms was simultaneously possible in this bispecific format, thus sandwich ELISA protocols in which only a bispecific would result in binding were established (see SI for details). Pleasingly, in all cases all non-bispecific controls showed no binding when compared with Fab $_{\text {RIT }}-\mathrm{AF} 488-\mathrm{Fab}_{\mathrm{TRA}}-\mathrm{Cy} 5.5$ 
31 and $\mathrm{Fab}_{\mathrm{TRA}}-\mathrm{Fab}_{\mathrm{CET}} 13$ and for both constructs, binding was detected for both antigens indicating that $\mathrm{Fab}_{\mathrm{TRA}}-\mathrm{Fab}_{\mathrm{CET}}$ 13/ $\mathrm{Fab}_{\mathrm{RIT}}-\mathrm{AF} 488-\mathrm{Fab}_{\mathrm{TRA}}-\mathrm{Cy} 5.531$ can indeed engage EGFR + HER2 / CD20 + HER2 simultaneously (Figure 11).
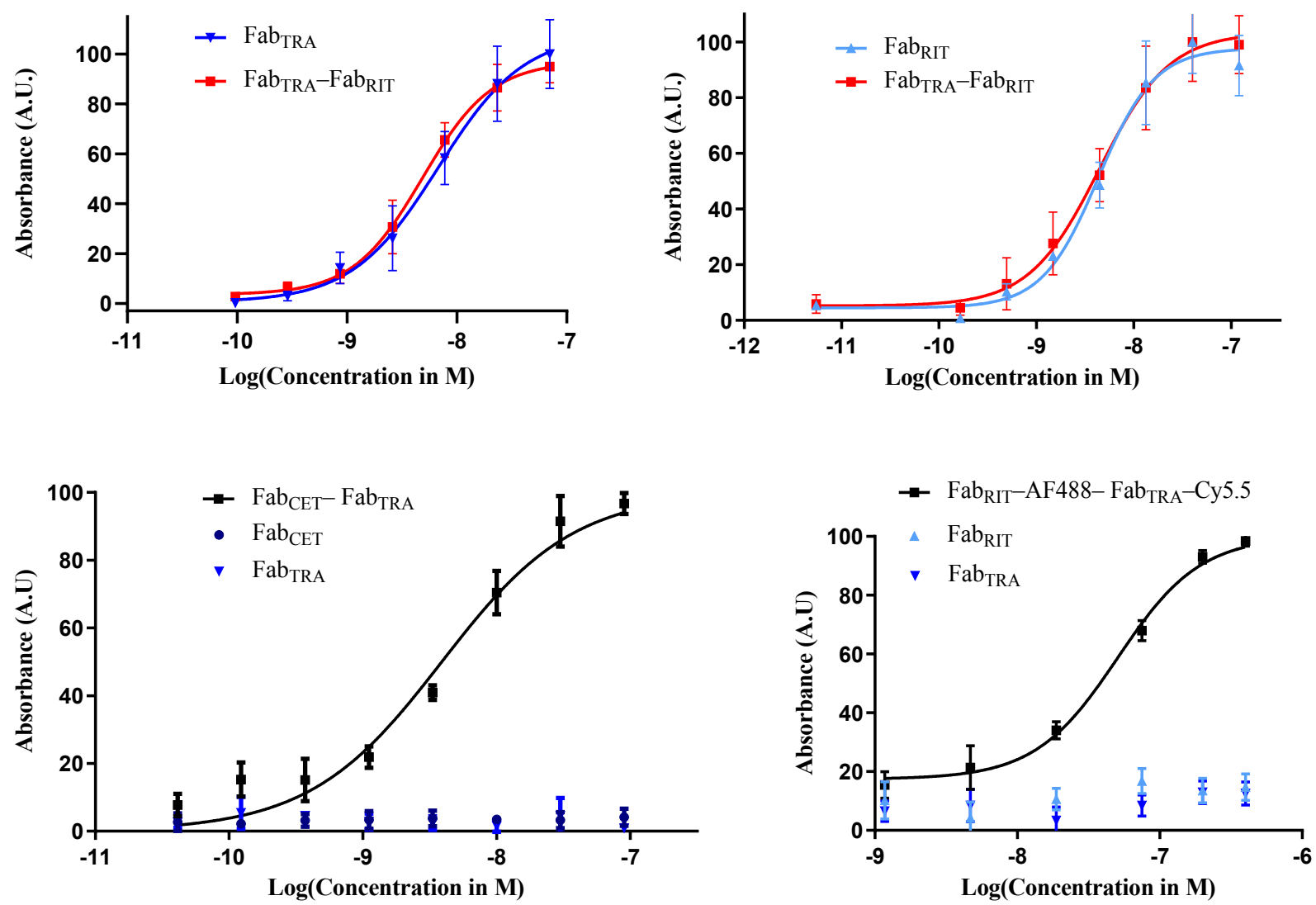

Figure 11: ELISA and sandwich ELISA analyses of Fab $_{\mathrm{RIT}}-\mathrm{AF} 488-\mathrm{Fab}_{\mathrm{TRA}}-\mathrm{Cy} 5.531$ and $\mathrm{Fab}_{\mathrm{TRA}}-\mathrm{Fab}_{\mathrm{CET}}$ 13.

\section{Discussion}

In conclusion, we have developed a novel modular approach to assemble native antibody fragments to generate bispecifics in high yield and purity. Our approach enables further controlled and site-selective dual modifications of the chemically-constructed BsAbs which retains binding for both its targets. At its core, this strategy relies on the fine tuning of chemically orthogonal and bioorthogonal reactions to sequentially assemble all the building blocks in a reliable and modular fashion. This allows facile combination of antibodies and could be used to rapidly generate a library of BsAbs without the need for genetic engineering. We envisaged that this versatility can pave the way not only to novel bispecifics-based therapeutics, especially in laboratories where antibody engineering techniques are not easily accessible, but also in fields outside of antibody-based therapeutics in which protein-protein conjugates need to be prepared and functionalised. 


\section{Conflicts of interest}

There are no immediate conflicts to declare, but we make clear that J.R.B., S.C. and V.C. are Directors of the spin-out ThioLogics.

\section{Author contribution}

V.C., A.M., S.C. and J.R.B. conceived and designed the project; A.M., V.C. and J.R.B. conceived and designed the chemistry and chemical biology experiments; A.M., C.J.B. and P.S. performed the chemistry experiments; A.M., J.C.F.N. and P.S. performed the chemical biology experiments; A.M., V.C. and C.B. analysed the data; AM, S.C. and V.C. co-wrote the paper.

\section{Acknowledgements}

We gratefully acknowledge the EPSRC (EP/M01792X/1) for funding A.M., the EPSRC (CASE Award with LifeArc, 173621) for funding CB, the European Union's Horizon 2020 research and innovation programme under the Marie Skłodowska-Curie grant agreement No. 675007 for funding J.C.F.N, Wellcome Trust for funding P.S. We also acknowledge the UCL Chemistry Mass Spectrometry (MS) Facility (Dr Kersti Karu and Dr Xiaoping Yang) for protein analysis, and the EPSRC UK National MS Facility (Swansea).

\section{Supporting information}

Supporting information containing general experimental details including characterisation and evaluation of bioconjugates is available.

\section{References}

1. Scott, A. M., Wolchok, J. D., and Old, L. J. (2012) Antibody therapy of cancer. Nat. Rev. Cancer 12, $278-287$.

2. Chudasama, V., Maruani, A., and Caddick, S. (2016) Recent advances in the construction of antibody-drug conjugates. Nat. Chem. 8, 114-119.

3. Weiner, G. J. (2015) Building better monoclonal antibody-based therapeutics. Nat. Rev. Cancer 15, 361-370.

4. Maruani, A. (2018) Bispecifics and antibody-drug conjugates: A positive synergy. Drug Discov. Today Technol. 30, 55-61.

5. Henricks, L. M., Schellens, J. H., Huitema, A. D., and Beijnen, J. H. (2015) The use of combinations of monoclonal antibodies in clinical oncology. Cancer Treat. Rev. 41, 859-867.

6. Staerz, U. D., Kanagawa, O., and Bevan, M. J. (1985) Hybrid antibodies can target sites for attack by T cells. Nature 314, 628-631.

7. Milstein, C., and Cuello, A. C. (1983) Hybrid hybridomas and their use in immunohistochemistry. Nature 305, 537-540.

8. Brinkmann, U., and Kontermann, R. E. (2017) The making of bispecific antibodies. $m A b s 9,182-$ 212.

9. Sedykh, S. E., Prinz, V. V., Buneva, V. N., and Nevinsky, G. A. (2018) Bispecific antibodies: design, therapy, perspectives. Drug Des. Devel. Ther. 12, 195-208.

10. Curnow, R. T. (1997) Clinical experience with CD64-directed immunotherapy. An overview. Cancer Immunol. Immunother. 45, 210-215.

11. Valone, F. H., Kaufman, P. A., Guyre, P. M., Lewis, L. D., Memoli, V., Deo, Y., Graziano, R., 
Fisher, J. L., Meyer, L., and Mrozek-Orlowski, M. (1995) Phase Ia/Ib trial of bispecific antibody MDX-210 in patients with advanced breast or ovarian cancer that overexpresses the proto-oncogene HER-2/neu. J. Clin. Oncol. 13, 2281-2292.

12. Posey, J. A., Raspet, R., Verma, U., Deo, Y. M., Keller, T., Marshall, J. L., Hodgson, J., Mazumder, A., and Hawkins, M. J. (1999) A Pilot Trial of GM-CSF and MDX-H210 in Patients with erbB-2-Positive Advanced Malignancies. J. Immunother. 22, 371.

13. James, N. D., Atherton, P. J., Jones, J., Howie, A. J., Tchekmedyian, S., and Curnow, R. T. (2001) A phase II study of the bispecific antibody MDX-H210 (anti-HER2 $\times$ CD64) with GM-CSF in HER2+ advanced prostate cancer. Br. J. Cancer 85, 152-156.

14. Borchmann, P. (2002) Phase 1 trial of the novel bispecific molecule H22xKi-4 in patients with refractory Hodgkin lymphoma. Blood 100, 3101-3107.

15. Kim, C. H., Axup, J. Y., Dubrovska, A., Kazane, S. A., Hutchins, B. A., Wold, E. D., Smider, V. V., and Schultz, P. G. (2012) Synthesis of bispecific antibodies using genetically encoded unnatural amino acids. J. Am. Chem. Soc. 134, 9918-9921.

16. Khalili, H., Godwin, A., Choi, J. W., Lever, R., Khaw, P. T., and Brocchini, S. (2013) Fab-PEGFab as a potential antibody mimetic. Bioconjugate Chem. 24, 1870-1882.

17. Kato, A., Kuratani, M., Yanagisawa, T., Ohtake, K., Hayashi, A., Amano, Y., Kimura, K., Yokoyama, S., Sakamoto, K., and Shiraishi, Y. (2017) Extensive Survey of Antibody Invariant Positions for Efficient Chemical Conjugation Using Expanded Genetic Codes. Bioconjugate Chem. 28, 2099-2108.

18. Patterson, J. T., Gros, E., Zhou, H., Atassi, G., Kerwin, L., Carmody, L., Zhu, T., Jones, B., Fu, Y., and Kaufmann, G. F. (2017) Chemically generated IgG2 bispecific antibodies through disulfide bridging. Bioorg. Med. Chem. Lett. 27, 3647-3652.

19. Walseng, E., Nelson, C. G., Qi, J., Nanna, A. R., Roush, W. R., Goswami, R. K., Sinha, S. C., Burke, T. R., Jr., and Rader, C. (2016) Chemically Programmed Bispecific Antibodies in Diabody Format. J. Biol. Chem. 291, 19661-19673.

20. Forte, N., Livanos, M., Miranda, E., Morais, M., Yang, X., Rajkumar, V. S., Chester, K. A., Chudasama, V., and Baker, J. R. (2018) Tuning the Hydrolytic Stability of Next Generation Maleimide Cross-Linkers Enables Access to Albumin-Antibody Fragment Conjugates and triscFvs. Bioconjugate Chem. 29, 486-492.

21. Hull, E. A., Livanos, M., Miranda, E., Smith, M. E. B., Chester, K. A., and Baker, J. R. (2014) Homogeneous Bispecifics by Disulfide Bridging. Bioconjugate Chem. 25, 1395-1401.

22. Patterson, J. T., Isaacson, J., Kerwin, L., Atassi, G., Duggal, R., Bresson, D., Zhu, T., Zhou, H., Fu, Y., and Kaufmann, G. F. (2017) PSMA-targeted bispecific Fab conjugates that engage T cells. Bioorg Med Chem Lett 27, 5490-5495.

23. Glennie, M. J., McBride, H. M., Worth, A. T., and Stevenson, G. T. (1987) Preparation and performance of bispecific F(ab' gamma)2 antibody containing thioether-linked Fab' gamma fragments. J. Immunol. 139, 2367-2375.

24. Patke, S., Li, J., Wang, P., Slaga, D., Johnston, J., Bhakta, S., Panowski, S., Sun, L. L., Junttila, T., Scheer, J. M., et al. (2017) bisFabs: Tools for rapidly screening hybridoma IgGs for their activities as bispecific antibodies. $m A b s$ 9, 430-437.

25. McKay, Craig S., and Finn, M. G. (2014) Click Chemistry in Complex Mixtures: Bioorthogonal Bioconjugation. Chem. Biol. 21, 1075-1101.

26. Maruani, A., Richards, D. A., and Chudasama, V. (2016) Dual modification of biomolecules. Org. Biomol. Chem. 14, 6165-6178.

27. Maruani, A., Smith, M. E., Miranda, E., Chester, K. A., Chudasama, V., and Caddick, S. (2015) A plug-and-play approach to antibody-based therapeutics via a chemoselective dual click strategy. Nat. Commun. 6, 6645.

28. Robinson, E., Nunes, J. P. M., Vassileva, V., Maruani, A., Nogueira, J. C. F., Smith, M. E. B., 
Pedley, R. B., Caddick, S., Baker, J. R., and Chudasama, V. (2017) Pyridazinediones deliver potent, stable, targeted and efficacious antibody-drug conjugates (ADCs) with a controlled loading of 4 drugs per antibody. RSC Advances 7, 9073-9077.

29. Lee, M. T. W., Maruani, A., Baker, J. R., Caddick, S., and Chudasama, V. (2016) Next-generation disulfide stapling: reduction and functional re-bridging all in one. Chem. Sci. 7, 799-802.

30. Lee, M. T. W., Maruani, A., Richards, D. A., Baker, J. R., Caddick, S., and Chudasama, V. (2017) Enabling the controlled assembly of antibody conjugates with a loading of two modules without antibody engineering. Chem. Sci. 8, 2056-2060.

31. Maruani, A., Alom, S., Canavelli, P., Lee, M. T., Morgan, R. E., Chudasama, V., and Caddick, S. (2015) A mild TCEP-based para-azidobenzyl cleavage strategy to transform reversible cysteine thiol labelling reagents into irreversible conjugates. Chem. Commun. 51, 5279-5282.

32. Bryden, F., Maruani, A., Rodrigues, J. M. M., Cheng, M. H. Y., Savoie, H., Beeby, A., Chudasama, V., and Boyle, R. W. (2018) Assembly of High-Potency Photosensitizer-Antibody Conjugates through Application of Dendron Multiplier Technology. Bioconjugate Chem. 29, 176-181.

33. Maruani, A., Savoie, H., Bryden, F., Caddick, S., Boyle, R., and Chudasama, V. (2015) Siteselective multi-porphyrin attachment enables the formation of a next-generation antibody-based photodynamic therapeutic. Chem. Commun. 51, 15304-15307.

34. Greene, M. K., Richards, D. A., Nogueira, J. C. F., Campbell, K., Smyth, P., Fernández, M., Scott, C. J., and Chudasama, V. (2018) Forming next-generation antibody-nanoparticle conjugates through the oriented installation of non-engineered antibody fragments. Chem. Sci. 9, 79-87.

35. Zhao, Y., Gutshall, L., Jiang, H., Baker, A., Beil, E., Obmolova, G., Carton, J., Taudte, S., and Amegadzie, B. (2009) Two routes for production and purification of Fab fragments in biopharmaceutical discovery research: Papain digestion of $\mathrm{mAb}$ and transient expression in mammalian cells. Protein Expr. Purif. 67, 182-189.

36. Rezvani, A. R., and Maloney, D. G. (2011) Rituximab resistance. Best Pract. Res. Clin. Haematol. 24, 203-216.

37. Chames, P., and Baty, D. (2009) Bispecific antibodies for cancer therapy: the light at the end of the tunnel? $m A$ Abs 1, 539-547.

38. Gall, J. M., Davol, P. A., Grabert, R. C., Deaver, M., and Lum, L. G. (2005) T cells armed with anti-CD3 $\mathrm{x}$ anti-CD20 bispecific antibody enhance killing of CD20+ malignant B cells and bypass complement-mediated rituximab resistance in vitro. Exp. Hematol. 33, 452-459.

39. Ding, L., Tian, C., Feng, S., Fida, G., Zhang, C., Ma, Y., Ai, G., Achilefu, S., and Gu, Y. (2015) Small Sized EGFR1 and HER2 Specific Bifunctional Antibody for Targeted Cancer Therapy. Theranostics 5, 378-398.

40. Mazor, Y., Sachsenmeier, K. F., Yang, C., Hansen, A., Filderman, J., Mulgrew, K., Wu, H., and Dall'Acqua, W. F. (2017) Enhanced tumor-targeting selectivity by modulating bispecific antibody binding affinity and format valence. Sci. Rep. 7, 40098.

41. Oliveira, B. L., Guo, Z., and Bernardes, G. J. L. (2017) Inverse electron demand Diels-Alder reactions in chemical biology. Chem. Soc. Rev. 46, 4895-4950.

42. Lang, K., Davis, L., Torres-Kolbus, J., Chou, C., Deiters, A., and Chin, J. W. (2012) Genetically encoded norbornene directs site-specific cellular protein labelling via a rapid bioorthogonal reaction. Nat. Chem. 4, 298-304.

43. Wang, D., Chen, W., Zheng, Y., Dai, C., Wang, K., Ke, B., and Wang, B. (2014) 3,6-Substituted1,2,4,5-tetrazines: tuning reaction rates for staged labeling applications. Org. Biomol. Chem. 12, 3950 .

44. Dommerholt, J., Rutjes, F. P. J. T., and van Delft, F. L. (2016) Strain-Promoted 1,3-Dipolar Cycloaddition of Cycloalkynes and Organic Azides. Top. Curr. Chem. 374.

45. Borrmann, A., Milles, S., Plass, T., Dommerholt, J., Verkade, J. M. M., Wießler, M., Schultz, C., van Hest, J. C. M., van Delft, F. L., and Lemke, E. A. (2012) Genetic Encoding of a 
Bicyclo[6.1.0]nonyne-Charged Amino Acid Enables Fast Cellular Protein Imaging by MetalFree Ligation. ChemBioChem 13, 2094-2099.

46. Karver, M. R., Weissleder, R., and Hilderbrand, S. A. (2011) Synthesis and Evaluation of a Series of 1,2,4,5-Tetrazines for Bioorthogonal Conjugation. Bioconjugate Chem. 22, 2263-2270.

47. Bahou, C., Richards, D. A., Maruani, A., Love, E. A., Javaid, F., Caddick, S., Baker, J. R., and Chudasama, V. (2018) Highly homogeneous antibody modification through optimisation of the synthesis and conjugation of functionalised dibromopyridazinediones. Org. Biomol. Chem. 16, 1359-1366.

48. Evans, H. L., Nguyen, Q.-D., Carroll, L. S., Kaliszczak, M., Twyman, F. J., Spivey, A. C., and Aboagye, E. O. (2014) A bioorthogonal 68Ga-labelling strategy for rapid in vivo imaging. Chem. Commun. 50, 9557-9560.

49. Eising, S., Engwerda, A. H. J., Riedijk, X., Bickelhaupt, F. M., and Bonger, K. M. (2018) Highly Stable and Selective Tetrazines for the Coordination-Assisted Bioorthogonal Ligation with Vinylboronic Acids. Bioconjugate Chem. 29, 3054-3059. 